\title{
SUPRAMOLECULAR ASSEMBLED NANOGEL MADE OF MANNAN
}

\author{
Sílvia A. Ferreira, ${ }^{\mathrm{a}}$ Manuel Vilanova, ${ }^{\mathrm{b}}$ Francisco Miguel Gama, ${ }^{\mathrm{a}}$ \\ ${ }^{a}$ Department of Biological Engineering \\ ${ }^{\mathrm{b}}$ Instituto de Ciências Biomédicas de Abel Salazar, Universidade do Porto \\ E-mail: silviarmferreira@deb.uminho.pt
}

\section{KEYWORDS}

Mannan, nanogel, supramolecular assembly, Michael addition.

\section{INTRODUCTION}

The supramolecular assembled nanogel made of mannan was synthesed and characterized with the purpose to obtain a potential pharmaceutical delivery system able to work both as a therapeutic and prophylactic vaccine adjuvant and antigen carrier. These systems are expected to perform as carriers for proteins and peptides, acting like antigens, optimizing delivery to antigen-presenting cells, by targeting their mannose receptors. Immunity might be improved conjugating this system with other immune response modifiers.

\section{MATERIALS AND METHODS}

The supramolecular assembly of amphiphilic mannan (mannan- $\mathrm{C}_{16}$ or $\mathrm{MVC}_{16}$ ), synthesized by the Michael addition of hydrophobic 1-hexadecanethiol $\left(\mathrm{C}_{16}\right)$ to vinyl methacrylated mannan (VMA), originates in aqueous medium the formation of a nanogel, stabilized by hydrophobic interactions among alkyl chains.
The physic-chemical properties of the resulting nanogel were characterized - size, shape, charge and stability during storage - using fluorescence spectroscopy, cryo-field emission scanning electron microscopy (cryo-FESEM) and dynamic light scattering (DLS).

\section{RESULTS AND DISCUSSION}

The biopolymeric low cost and simple macromolecular micelles were easely produced by the Michael addition of hydrophobic $\mathrm{C}_{16}$ to vinyl methacrylated mannan (Figure 1). The critical aggregation concentration (cac), calculated by fluorescence spectroscopy ranged between 0.002 and $0.01 \mathrm{mg} / \mathrm{mL}$, depending on the polymer degree of substitution. The cryo-FESEM showed spherical macromolecular micelles with diameters between 100 and $500 \mathrm{~nm}$ (Figure 2).

The DLS analysis revealed a nearly neutral negatively charged and polydisperse colloidal system, stable over a six months storage period, with mean hydrodynamic diameter between 50 and $140 \mathrm{~nm}$, depending on the polymer degree of substitution (Figure 3 and 4).

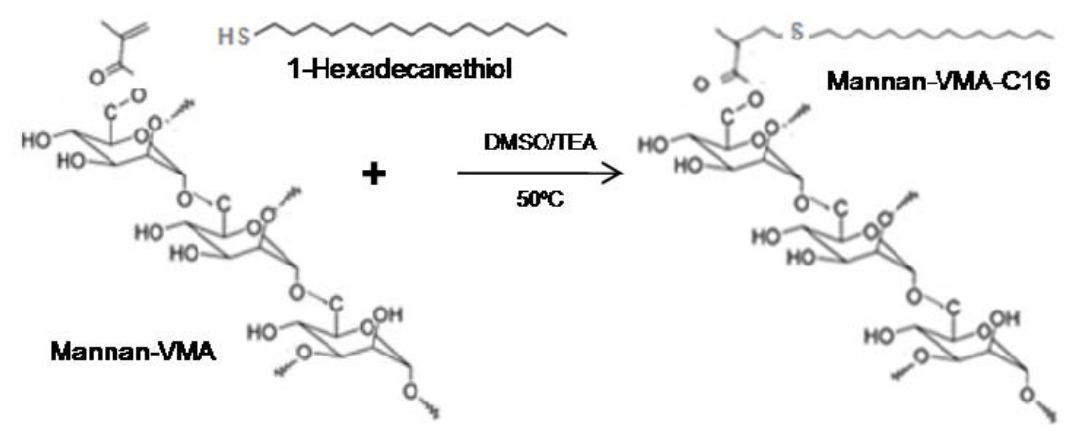

Figure 1: Synthesis of mannan- $\mathrm{C}_{16}$ 


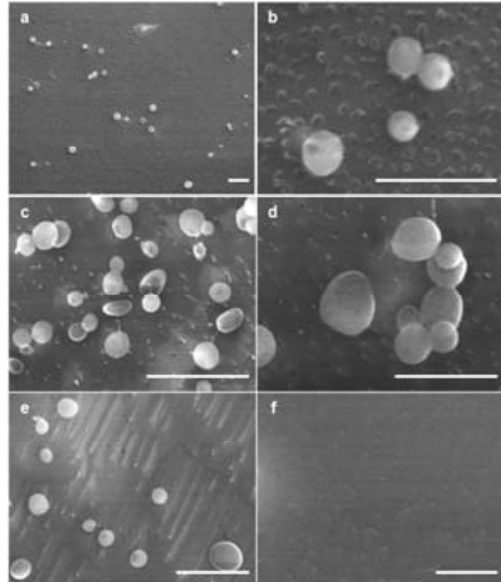

Figure 2: The cryo-FESEM negatively stained micrographs of mannan- $\mathrm{C}_{16}$ (scale bar $\left.=1 \mu \mathrm{m}\right):(a, b)$ $\mathrm{MVC}_{16}-20-8,(c, d) \mathrm{MVC}_{16}-20-11$, (e) $\mathrm{MVC}_{16}-20-16$ and $(f)$ solvent

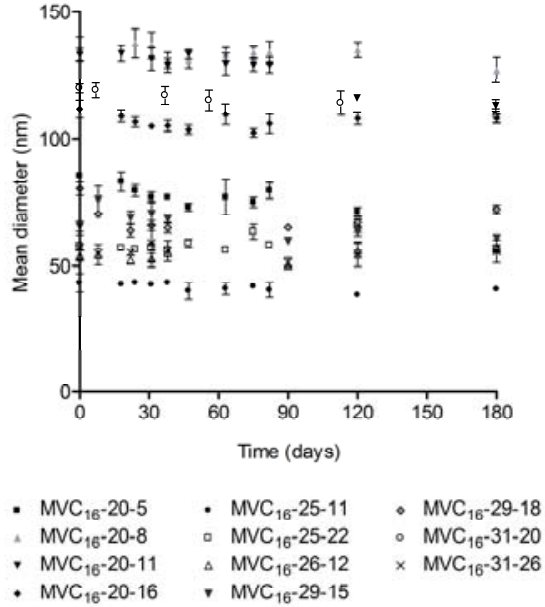

Figure 3: The size of mannan- $\mathrm{C}_{16}$ water dispersions (1 $\mathrm{mg} / \mathrm{mL}$ ) over a six months storage period, at room temperature $\left(25^{\circ} \mathrm{C}\right)$, measured periodically by DLS (mean \pm S.D., $\mathrm{n}=10$ )

Size Distribution by Intensity
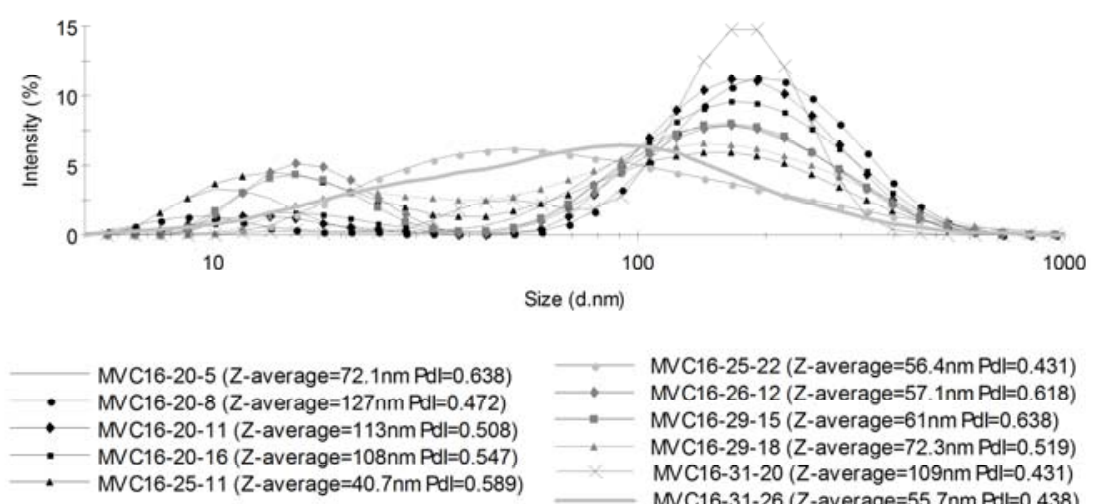

MVC16-25-22 (Z-average $=56.4 \mathrm{~nm} \mathrm{Pdl}=0.431)$ MNC16-26-12 (Z-average $=57.1 \mathrm{~nm} \mathrm{Pdl}=0.618)$ MVC16-29-15 (Z-average $=61 \mathrm{~nm} P d \mathrm{~d}=0.638)$ MVC16-29-18 (Z-average $=72.3 \mathrm{~nm} \mathrm{Pdl}=0.519)$ MVC16-31-20 (Z-average $=109 \mathrm{~nm} \mathrm{Pdl}=0.431)$ MVC16-31-26 (Z-average $=55.7 \mathrm{~nm} P d l=0.438)$

Figure 4: The size distribution by intensity, z-average and PdI of the mannan- $\mathrm{C}_{16}$ water dispersions $(1 \mathrm{mg} / \mathrm{mL})$ measured by DLS (mean \pm S.D., $n=10$ ) after a six months storage period, at room temperature $\left(25^{\circ} \mathrm{C}\right)$

\section{CONCLUSIONS}

The supramolecular assembled amphiphilic nanogel made of mannan was designed with a versatile, easy, reproducible and low-cost method. Above the cac, spherical polydisperse macromolecular micelles revealed long-term stability in aqueous environment, with mean hydrodynamic diameter ranging between 50 and 140nm and nearly neutral negative surface charge.

\section{ACKNOWLEDGMENTS}

The authors thank the financial support by International Iberian Nanotechnology Laboratory (INL) and FCT, trough PTDC, is gratefully acknowledged.

\section{AUTHOR BIOGRAPHIES}

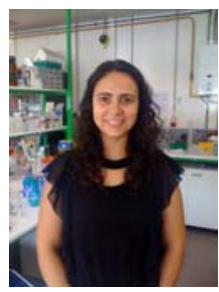

SILVIA A. FERREIRA was born in Santo Tirso, Portugal and went to the School of Pharmacy of University of Porto, where she studied pharmaceutical sciences and obtained her degree in 2007. She is a PhD student in FUNCARB - FUNctional CARBohydrates Nanobiotechnology Group, in IBB-Institute for Biotechnology and Bioengineering, Centre for Biological Engineering, Universidade do Minho, Braga, PORTUGAL. Her web-page can be found at http://www.ceb. uminho.pt/pessoas/pid.aspx? id $=249$. 